\title{
Impact of arterial hypertension on the cognitive function of patients between 45 and 65 years. Luis Vernaza Hospital, Guayaquil, Ecuador
}

\author{
Efecto de la hipertensión arterial en la función cognitiva \\ de pacientes de 45 a 65 años. Hospital Luis Vernaza, Guayaquil, Ecuador
}

\author{
Gabriel A. Zúñiga-Salazar ${ }^{1}$, Sofía M. Hincapié-Arias ${ }^{1}$, Erin E. Salazar-Bolaños ${ }^{1}$, Joffre J. Lara-Terán², \\ Silvia V. Cáceres-Vinueza ${ }^{3}$ and Yan C. Duarte-Vera ${ }^{3,4,5 *}$
}

${ }^{1}$ Department of Neurology, Hospital General Luis Vernaza; ${ }^{2}$ Department of Cardiology, Sociedad de Lucha Contra el Cáncer SOLCA; ${ }^{3}$ Faculty of Medical Sciences, Universidad de Guayaquil; ${ }^{4}$ Department of Cardiology, Hospital General Luis Vernaza; ${ }^{5}$ Department of Research, Sociedad Ecuatoriana de Cardiología. Guayaquil, Ecuador

\begin{abstract}
Introduction: Mild cognitive impairment (MCl) is an alteration of cognitive function that does not negatively affect the daily activities of the person. Modifiable risk factors such as hypertension could be involved in the acceleration of this process affecting people under 65 years of age. Early detection of $\mathrm{MCl}$ through the Montreal Cognitive Assessment (MoCA) in people with high blood pressure would help to formulate strategies for its effective control. Materials and methods: A cross-sectional observational study was designed. The population is hypertensive patients between 45 and 65 years old in Guayaquil. From a database of 570 patients, a call was made to patients who met the inclusion and exclusion criteria, for the evaluation of cognitive function through MoCA. Results: About $93.3 \%$ of the participants who underwent the MoCA test had a score lower than 26. The average of the total score was 18.9 , with $51.6 \%$ of the participants suffering from MCl. A negative correlation of $40 \%(-0.40)$ was obtained with $p=0.0015$ between years with arterial hypertension and the total result of the MoCA test. Conclusions: Through MoCA, the magnitude of cognitive deterioration in these patients could be quantified It was detected that the majority of the examined participants had a lower average score of the normal range. The figures obtained from the Pearson correlation values show trend activity, relating arterial hypertension, and deterioration of cognitive function.
\end{abstract}

Key words: Mild cognitive impairment. Arterial hypertension. Montreal cognitive assessment. Dementia. Memory. Cognitive function.

\section{Resumen}

Introducción: El deterioro cognitivo leve es una alteración de la función cognitiva que no afecta de manera negativa a las actividades diarias de la persona. Factores de riesgo modificables como la hipertensión arterial podrían intervenir en el aceleramiento de este proceso y afectar a personas menores de 65 años. Una detección temprana del deterioro cognitivo leve por

\section{Correspondence:}

*Yan C. Duarte Vera

E-mail: yancarlos_duartevera@yahoo.es
Available online: $04-12-2020$ Arch Cardiol Mex (Eng). 2020;90(3):258-266 www.archivoscardiologia.com 2604-7063 / @ 2020 Instituto Nacional de Cardiología Ignacio Chávez. Published by Permanyer. This is an open access article under the CC BY-NC-ND license (http://creativecommons.org/licenses/by-nc-nd/4.0/). 
medio del Montreal Cognitive Assesment (MoCA) en personas con hipertensión arterial ayudaría a idear medidas para su control eficaz. Materiales y métodos: Se diseñó un estudio de tipo observacional transversal. La población se integra con pacientes hipertensos de 45 a 65 años de Guayaquil. De una base de datos de 570 pacientes, se realizó un llamado a sujetos que cumplieran los criterios de inclusión y exclusión, para la evaluación de la función cognitiva por medio del MoCA. Resultados: El 93.3\% de los participantes sometidos a la prueba MoCA presentó un puntaje menor de 26. El promedio del puntaje total fue de 18.9 y el $51.6 \%$ de los participantes reveló deterioro cognitivo leve. Se obtuvo una correlación negativa del $40 \%$ (-0.40) con una $p=0.0015$ entre años con hipertensión arterial y el resultado total de la prueba MoCA. Conclusiones: Por medio del MoCA se pudo cuantificar la magnitud del deterioro cognitivo en estos pacientes. Se identificó que la mayoría de los participantes examinados presentaba un puntaje promedio menor del intervalo normal. Las cifras obtenidas de los valores de correlación de Pearson muestran una actividad tendencial y relación de la hipertensión arterial con el deterioro de la función cognitiva.

Palabras clave: Deterioro cognitivo leve. Hipertensión arterial. MoCA. Demencia. Memoria. Función cognitiva.

\section{Introduction}

Mortality rates among older individuals have decreased, while life expectancy has increased; consequently, there has been an increase in cases of dementia at global scale. Dementia is a syndrome characterized by progressive and irreversible loss of cognitive functions: attention, memory, executive function, visuospatial skills and language, and it interferes with the lifestyle of people who suffer from it and alters the lives of those who belong to their family circle, which makes it a major threat to public health ${ }^{1}$. It usually occurs in subjects older than 65 years. In 2015, there were 46.8 million people with dementia in the world. In the Americas, there were a total of 9.4 million individuals with dementia in 20152. In 2010, in Ecuador, 20.3\% of subjects aged 60 years and older showed cognitive impairment ${ }^{3}$.

Before reaching dementia, patients go through an intermediate state, between normal cognition and dementia, called mild cognitive impairment (MCl), which does not interfere with people's normal daily activities ${ }^{4}$. This state is more common as people get older, but modifiable risk factors such as hypertension may intervene in the acceleration of this process and affect individuals younger than 65 years. Numerous studies have demonstrated the relationship between high blood pressure and dementia, but there is still scarce research on the existence of $\mathrm{MCl}$ in hypertensive patients younger than 65 years ${ }^{5}$.

Early identification of $\mathrm{MCl}$ through screening tests such as the Montreal Cognitive Assessment (MoCA) in patients with hypertension would help to implement treatments for its efficacious control and slowing down the cognitive impairment process, in addition to establishing strategies that help reduce the effect of possible dementia in these patients, given that intensive modification of risk factors, especially at between 45 and 65 years of age, has been observed to have the potential for delaying or preventing a considerable number dementia cases at global level $\mathrm{f}^{6,7}$

\section{$\mathrm{MCl}$}

The term $\mathrm{MCl}$ refers to an altered cognitive function that does not meet the criteria for dementia. In dementia, there is not only altered cognitive function but also negative consequences on the individual's daily activities, while in cognitive impairment there is no daily life alteration. This type of impairment can be classified in several ways; the most useful classifies the disorder in amnestic and non-amnestic types ${ }^{8}$.

\section{Types of $\mathrm{MCl}$}

$\mathrm{MCl}$ is divided in amnestic and non-amnestic types and each one is subdivided into single-domain and multiple-domains. Amnestic-type $\mathrm{MCl}$ is the most common and is more related to Alzheimer's disease. The criteria that were originally devised for $\mathrm{MCl}$ are currently used to define the single-domain amnestic type ${ }^{9}$.

These criteria include the following:

- Memory complaint, preferably corroborated by an informant

- Decrease in objective memory (for age and education level)

- Preserved general cognitive function

- Intact daily life activities

- Absence of dementia.

In the case of the multiple-domain amnestic type, there are alterations of other cognitive domains that are revealed after a properly conducted neuropsychological study. This type of $\mathrm{MCl}$ occurs in individuals who may suffer a slight alteration of their daily activities, 
but without incurring the criteria to consider them demented ${ }^{10}$.

On the other hand, non-amnestic $\mathrm{MCl}$, like the above, is sub-classified in a single subtype and in a subtype that analyzes several domains. The first one is characterized by alteration in a domain unrelated to memory, that is, it is related to the executive function, language or visuospatial skills. Patients of this group appear to have a lower risk of conversion to dementia. Depending on the domain, people with this $\mathrm{MCl}$ subtype can progress to other syndromes, such as frontotemporal dementia, primary progressive aphasia, Lewy body dementia, progressive supranuclear palsy, or corticobasal degeneration ${ }^{11}$.

In the case of $\mathrm{MCl}$ of the multiple domain non-amnestic type, patients who meet these criteria are affected in several domains, with a relative preservation of memory problems. Apparently, in these cases, there is an association with degenerative disorders such as Lewy body dementia or frontotemporal dementia, which are related to the, TDP-43, and $\alpha$ synuclein proteins ${ }^{12}$.

There is great variability in $\mathrm{MCl}$ epidemiology, due to the different types of tests used to assess it, loss of participants, and study randomness. On the other hand, values considerably differ from each other due to the populations that are comprised, due to a higher prevalence at older ages. In this case, there is considerable difference when comparing the results of 40-60-year-old patients with those of subjects aged from 60 to 70 years. The approximate range is 5-13 people for every 1000 who suffer $\mathrm{MCl}$ every year.

In Ecuador, there are few studies about the incidence or prevalence of $\mathrm{MCl}$, especially in populations younger than 65 years. In a hospital-based analysis carried out in 2012, out of 212 patients, $15 \%$ were observed to show $\mathrm{MCl}$ in a population aged 65-85 years. The risk factors associated with this alteration include hypertension, depression, level of education, and older age.

Regarding cognitive function, the main complaint of patients with $\mathrm{MCl}$ is memory problems, such as remembering names, places, or actions executed minutes ago. Unlike patients with dementia or Alzheimer's disease, individuals with $\mathrm{MCl}$ are generally concerned about mnemonic alterations.

As for neuropsychiatric symptoms, clinical manifestations related to patients with $\mathrm{MCl}$, such as irritability, anxiety, apathy, and aggressiveness are identified (with depression being the most common of all). These symptoms are mild, and the form of presentation is what differentiates dementia from Alzheimer's disease, in which symptoms are observed with more severity and frequency ${ }^{13}$.
Regarding the frequency depression appears with in patients with $\mathrm{MCl}$, some studies have observed that depression and its severity are greater in individuals with $\mathrm{MCl}$ and that there is a progressive reduction of their cognitive function ${ }^{14}$.

$\mathrm{MCl}$ diagnosis can be established by neuroimaging or laboratory tests. Regular neuroimaging is not recommended in usual $\mathrm{MCl}$ clinical evaluation. It can be requested as part of an investigation to determine the causes and prognosis of $\mathrm{MCl}$. Among the possible studies, structural magnetic resonance imaging (MRI) can be useful to identify $\mathrm{MCl}$ in subjects with higher probability of progressing from $\mathrm{MCl}$ to dementia. One of the images that can be visualized on MRI and that indicate $\mathrm{MCl}$ is hippocampal volume measurement showing signs consistent with atrophy, which is also related to the risk of progression to dementia. In general, MRI is not used as a standard imaging study to determine $\mathrm{MCl}$, but according to the medical history, it can be used as a tool to rule out anomalies such as subdural hematomas, cerebrovascular events, brain neoplasms, and other causes. Another type of neuroimaging tool that is useful to investigate $\mathrm{MCl}$ is positron-emission tomography with fluorodeoxyglucose. This type of imaging resource is useful in patients with $\mathrm{MCl}$ caused by Alzheimer's disease, given that regions of hypometabolism and, in more advanced cases, presence of amyloid, are detected in the brain ${ }^{15}$.

As for laboratory tests, general blood tests, such as blood count, electrolytes, blood glucose, calcium, thyroid hormones, Vitamin B12, and folate are obtained to rule out other disorders and to recognize the most common causes of cognitive impairment. According to Clarfield, in a meta-analysis, about $9 \%$ of the causes of cognitive deterioration were observed to be due to reversible factors, including infections, hypermagnesemia, hyperglycemia, and Vitamin B12 deficiency or liver function alterations. Another laboratory test is cerebrospinal fluid analysis. This test is useful to detect $\tau$ protein in patients with high probability of future dementia ${ }^{16}$.

At present, there is no approved pharmacological treatment to treat $\mathrm{MCl}$; only patient risk factors are controlled, information is provided, and recommendations are issued to maximize well-being by reducing these factors. Symptoms of depression are alleviated with the help of antidepressant treatment. Although treating the depressive symptoms is necessary, a negative effect on cognitive function has been documented, especially in the elderly, with the prescription of anticholinergics ${ }^{17}$. Some studies have assessed the effectiveness of certain medications to avoid $\mathrm{MCl}$ progression; these include the use of acetylcholinesterase inhibitors in 


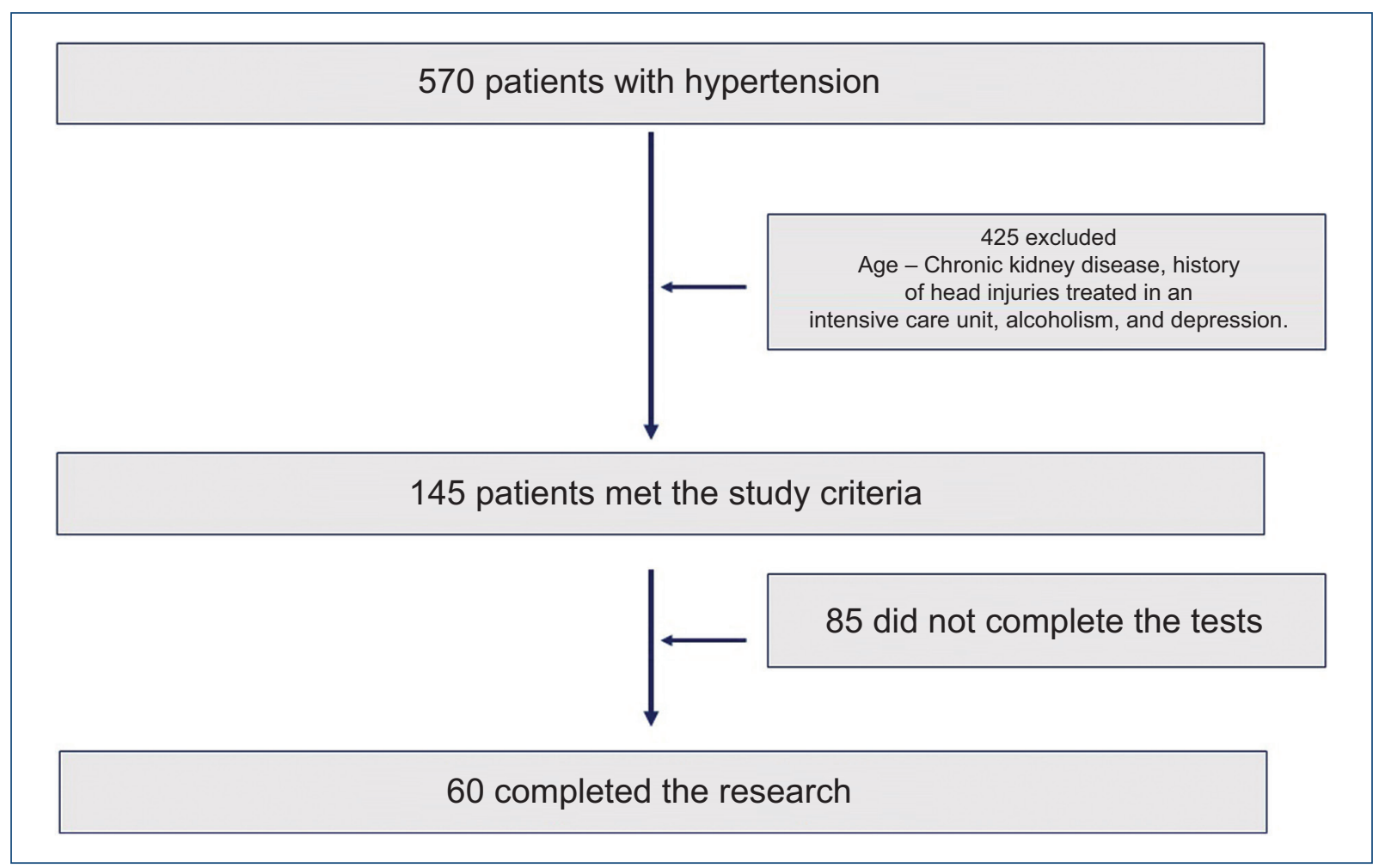

Figure 1. Flow chart for patients with hypertension.

patients with high risk for developing Alzheimer's disease in the future. So far, there are no studies that approve their consumption in patients ${ }^{18}$.

\section{Materials and methods}

\section{Research hypothesis}

Hypertension is associated with cognitive function early impairment in middle-aged people.

\section{General objective}

The general objective of the study was to determine the effect of high blood pressure on cognitive function in patients aged 45-65 years.

\section{Specific objectives}

The specific objectives of the study are as follows:

- To detect cognitive function impairment in hypertensive subjects aged 45-65 years.

- To quantify the magnitude of cognitive function impairment in hypertensive patients aged 45-65 years.
- To specify the cognitive function elements that are most affected in hypertensive subjects aged 45-65 years.

- To establish a link between the time with hypertension and cognitive impairment.

\section{Participants}

From a 570-patient database, obtained from the Cardiology Department of the Luis Vernaza Hospital outpatient clinic, 145 individuals met the inclusion and exclusion criteria, out of which only 60 completed the tests and agreed to be part of the study, which was carried out in accordance with the guidelines of good clinical practice and ethical standards for experimentation in human subjects established by the Declaration of Helsinki. Each patient granted informed consent to be included in this study. The rest of variables were obtained from the database included in the hospital computer system or from the patient medical history (Fig. 1).

\section{Inclusion criteria}

Middle-aged men and women (45-65 years) with a previous diagnosis of hypertension and individuals with 
at least complete primary education were included in the study.

\section{Exclusion criteria}

Individuals with a history of stroke, dementia, any degree of disability that would prevent conducting the MoCA test, chronic kidney disease, current treatment with hemodialysis, history of head injury treated in an intensive care unit, alcoholism, and depression were excluded from the study.

\section{Blood pressure measurement}

Blood pressure was measured with a digital sphygmomanometer (OMRON HEM7130) before the patients were evaluated with the MoCA. Individuals felt comfortable and remained seated for at least $5 \mathrm{~min}$ before the measurement, which was carried out with the individual in the sitting position.

\section{Neurocognitive test}

The neurocognitive test of choice in the study was the MoCA. The evaluator, which in this case was one of the researchers, conducted the test directly, and it was carried out at one of the offices of the cardiology area in the hospital outpatient clinic, individually, and without distractions. The evaluator obtained and interpreted the results according to the test instructions.

Maximum duration of the test according to the instructions was no longer than $10 \mathrm{~min}$. Highest score is 30 points. A score equal to or higher than 26 was considered normal; a score of 18-25 represented $\mathrm{MCl}$; from 10 to 17 was regarded as moderate cognitive impairment; and < 10 was assumed as severe cognitive impairment.

MoCA evaluates the following cognitive functions: visuospatial/executive skills, identification, memory, attention, language, abstraction, delayed recall, and orientation.

\section{Design and statistics}

A cross-sectional, observational study was designed. The population in this case was constituted of hypertensive patients aged 45-65 years under the care of the outpatient clinic of the Luis Vernaza Hospital in Guayaquil within the 2017-2018 period (Table 1). By means of a database compiled and processed in Excel, the

Table 1. Demographic characteristics of the sample

\section{Variable}

Age, mean

Women, $\mathrm{n}(\%)$

$\mathrm{SBP}$, mean in $\mathrm{mmHg}$

DBP, mean in $\mathrm{mmHg}$

MBP, mean in $\mathrm{mmHg}$

Years of HBP, mean (years)

Diabetes mellitus, $\mathrm{n}(\%)$

Dyslipidemia, n (\%)

Hypothyroidism, n (\%)

Smoking, $\mathrm{n}(\%)$

Primary education, $\mathrm{n}(\%)$

Secondary education, $\mathrm{n}(\%)$

Higher education, $\mathrm{n}(\%)$

DBP: diastolic blood pressure; HBP: high blood pressure; MBP: mean blood pressure; SBP: systolic blood pressure.

analyses were executed with the RStudio statistical program and the results were plotted using STATA.

\section{Results}

Of the patients who underwent the MoCA test, $63 \%$ (38) corresponded to women. The age range of this study was from 45 to 65 years, with 58 years as the mean age of those examined. When all the points on the MoCA test are added, a maximum of 30 points is obtained, with a score higher than or equal to 26 being normal. One point is added if the examinee has 12 years or less of education. As seen in figure 2, 93.3\% of participants had a score lower than 26.

An average of the scores obtained not only for the entire study but also for each one of the areas that make up the MoCA test was recorded. Total score average was 18.9 , with a median of 18.5 , and a standard deviation of 4.35 (Fig. 3)

Three degrees of cognitive impairment severity can be distinguished according to the MoCA test: mild, moderate, and severe (Table 2). Table 3 details the score percentage for each of the cognitive functions: in the visuospatial/executive area, average score was 2.36 , and with $47.2 \%$ of total score in this area. In the denomination area, an average of 2.23 and $74.3 \%$ of 


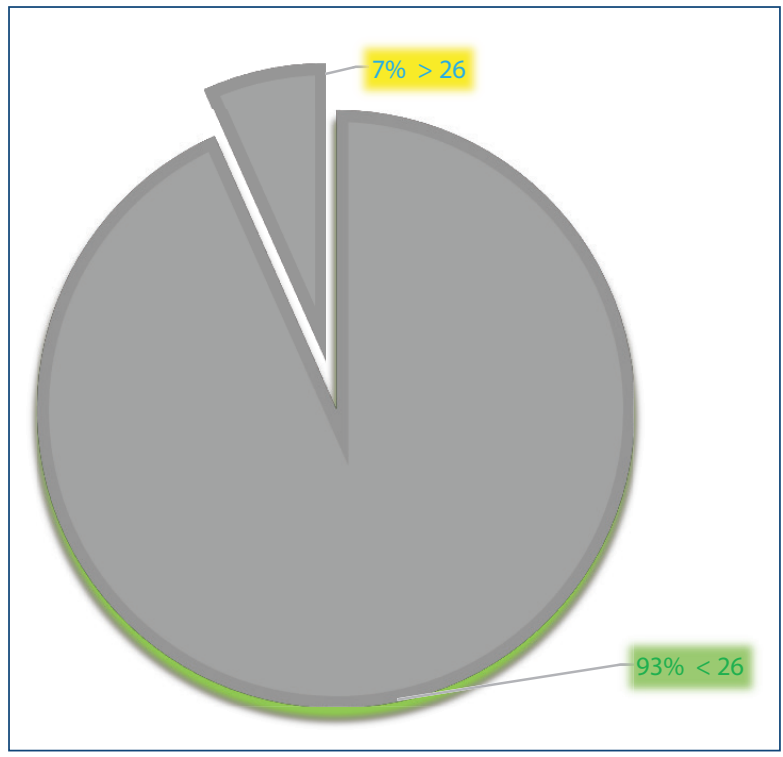

Figure 2. Representation of the percentage of patients who had a score higher or lower than 26 on the montreal cognitive assessment test.

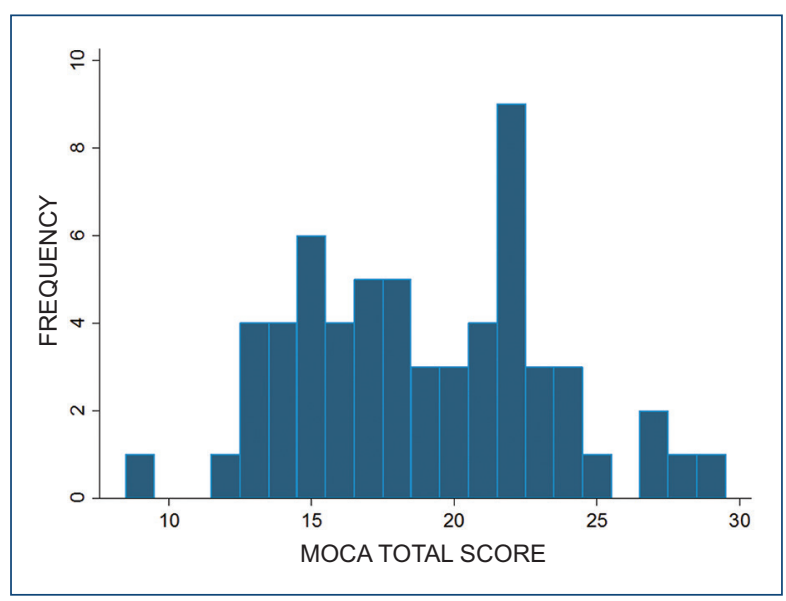

Figure 3. Histogram representing montreal cognitive assessment test total score and its frequency.

total score for the area were obtained. The memory area does not include points. The attention area is divided in three parts, with a total average of 3.56 and $59.3 \%$ for the score. The language area is divided in two parts, with a total score average of 1.46 and $48.6 \%$ for the score of that area. In the abstraction area, a point average of 1.25 and $62.5 \%$ for the score were recorded. In the deferred recall area, an average of 1.8 points and $36 \%$ for the score were identified. In the orientation area, an average of 5.65 points and $94.1 \%$ for the score were identified. The most negative result
Table 2. Cognitive impairment severity according to the MoCA test

\begin{tabular}{|l|c|c|c|}
\hline $\begin{array}{l}\text { Cognitive } \\
\text { impairment degrees }\end{array}$ & $\begin{array}{c}\text { MoCA } \\
\text { score }\end{array}$ & $\begin{array}{c}\text { Patient } \\
\text { frequency }\end{array}$ & $\begin{array}{c}\text { Percentage of } \\
\text { patients }\end{array}$ \\
\hline Mild & $18-25$ & 31 & 51.6 \\
\hline Moderate & $10-17$ & 24 & 40 \\
\hline Severe & $<10$ & 1 & 1.6 \\
\hline
\end{tabular}

MoCA: montreal cognitive assessment.

Table 3. Percentage of the score for each of the cognitive functions

\begin{tabular}{|l|c|c|}
\hline & Average & Percentage \\
\hline Executive score & 2.37 & 47.20 \\
\hline Identification score & 2.23 & 74.33 \\
\hline Attention score & 3.57 & 59.33 \\
\hline Language score & 1.47 & 48.66 \\
\hline Abstraction score & 1.25 & 62.50 \\
\hline Deferred recall score & 1.8 & 36 \\
\hline Orientation score & 5.65 & 94.16 \\
\hline
\end{tabular}

Table 4. Level of education and MoCA score average

\begin{tabular}{|l|c|c|}
\hline Level of education & $\begin{array}{c}\text { Patient } \\
\text { frequency }\end{array}$ & $\begin{array}{c}\text { MoCA score } \\
\text { average }\end{array}$ \\
\hline Primary school & 18 & 16.88 \\
\hline Secondary school & 26 & 19.57 \\
\hline Higher education & 16 & 20.06 \\
\hline MoCA: montreal cognitive assessment. & & \\
\hline
\end{tabular}

in the tests was in the female group, with an average score of 18.55. In men, average score was 19.5.

As regard the level of education, 18 participants had an education of $<13$ years, 26 had completed secondary school, and 16 had a higher education degree. The primary education level is accompanied by lower test scores, with an average of 16.88 , followed by secondary education with 19.57 and higher education with 20.06 (Table 4). A correlation analysis was carried out using the Spearman parameter between the years of education and MoCA test total result. There is a positive correlation of $31 \%(0.31)$ with $p=0.01$. This means 


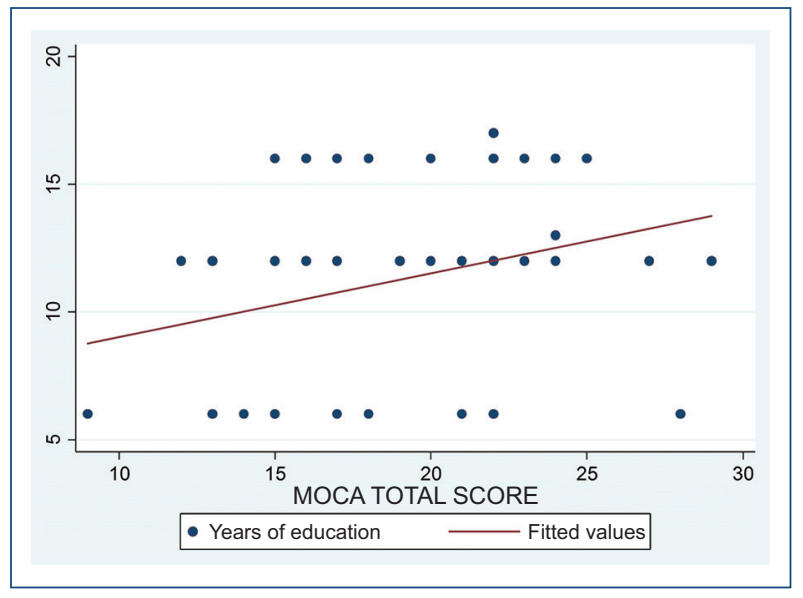

Figure 4. Scatter plot representing the correlation between years of education and montreal cognitive assessment test total score.

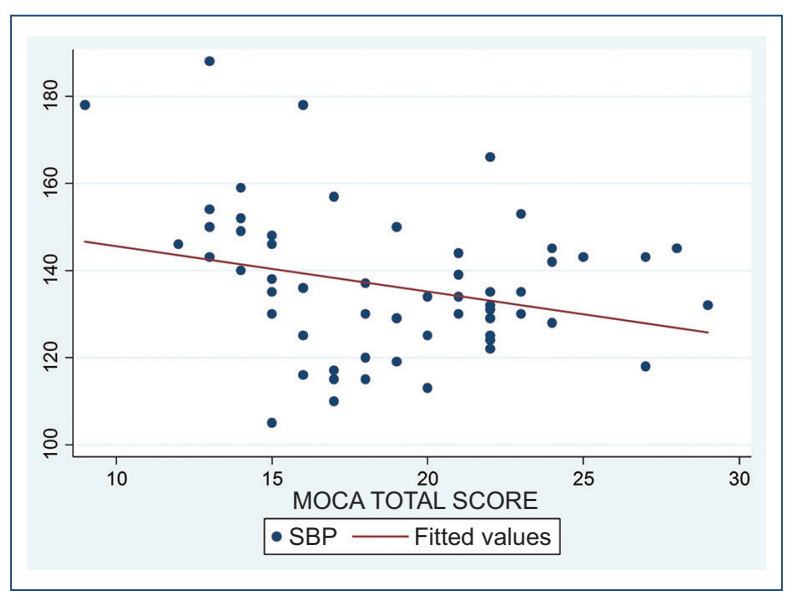

Figure 5. Scatter plot showing the correlation between systolic blood pressure and montreal cognitive assessment test total score.

that the more years of education a person has, the higher the score is. Although the correlation is not high, it could justify further investigation (Fig. 4).

All study participants had hypertension. Average mean arterial pressure before performing the test was $99.36 \mathrm{mmHg}$, that of systolic blood pressure was 136.28 $\mathrm{mmHg}$, and that of diastolic blood pressure, 80.9 $\mathrm{mmHg}$. Systolic blood pressure at the time of examination was correlated with the MoCA test end result using the Pearson instrument. A negative correlation of $26 \%$ $(-0.26)$ was obtained with $p=0.038$; that is, the higher the systolic blood pressure, the lower the total score. Although the correlation is not high, it could indicate the

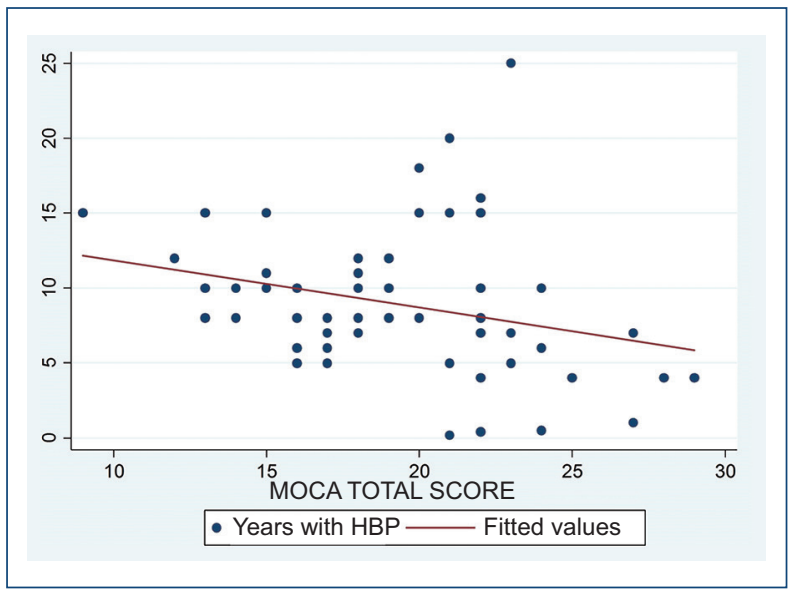

Figure 6. Scatter plot representing the correlation between years with high blood pressure and montreal cognitive assessment test total score.

need for further research in the future. Diastolic blood pressure was not correlated with a lower score (Fig. 5).

High blood pressure average duration in years since the moment of diagnosis was 8.2 years. The duration of hypertension and MoCA test total result were correlated using the Spearman parameter. There is a negative correlation of $40 \%(-0.40)$ with $p=0.001$. The longer duration of hypertension correlates with the lower score on the MoCA test. Although the correlation is not high, it could justify further research (Fig. 6).

Ten participants (16.6\%) have type 2 diabetes mellitus in addition to high blood pressure. Fourteen (23.3\%) have dyslipidemia as a comorbidity, while eight (13.3\%) suffer from hypothyroidism. Other anomalies of importance are not mentioned, since they appear in the exclusion criteria established for the study (Table 1).

\section{Discussion}

The results show a relationship between hypertension and cognitive impairment in this population group, which confirms the study hypothesis. This protocol and others like Guo et al. and In't Veld et al. have previously shown a link and even a causal relationship of hypertension with cognitive impairment ${ }^{19}$. Previous investigations focus on older adults (> 65 years), conversely to this research, which points toward a younger (45-65 years) and less studied population ${ }^{20}$.

Tzourio et al. and Gupta et al. studied cognitive impairment in middle-aged hypertensive subjects, and they recorded impairment in $8.3 \%$ and $14 \%$, respectively. The low percentage, in comparison with our findings, could 
perhaps be related to the use of the Mini-Mental State Examination (MMSE) in those studies, which is less sensitive to detect $\mathrm{MCl}^{21}$. In a study by Muela et al., the MoCa test was more sensitive than MMSE to identify $\mathrm{MCl}$ in hypertensive patients ${ }^{22}$. In this study, of higher to lower compromise, the most altered areas were: memory through delayed recall, executive functioning, language, attention, abstraction, identification, and orientation.

Vicario et al. ${ }^{23}$ showed an effect of hypertension on the executive function versus normotensive patients. Yaffe et al., Swan et al., and ladecola et al. demonstrate moderately robust evidence to support the claim that decreased processing speed and executive function are the most common cognitive changes related to hypertension ${ }^{24}$.

The participants of this study, in addition to hypertension, had other risk factors that can influence on cognitive function. Livingston et al., in their 2017 study, indicate the main risk factors that, when combined, can lead to cognitive function impairment. These are low level of education, middle-age hypertension, middle-age obesity, hearing loss, late life depression, diabetes, physical inactivity, smoking, and social isolation. In this study, the risk factors were a history of smoking, type 2 diabetes mellitus, dyslipidemia, hypothyroidism, and low level of education; the highest control was on hypertension due to its longer time of diagnosis and treatment ${ }^{25}$.

Due to a strict imposition of inclusion and exclusion criteria, and to the willingness of participants to partake in the study, only 60 subjects were included. Despite this low population, the figures obtained from Pearson's and Spearman correlation values show a tendency that relates hypertension to impaired cognitive function, whose trend probably could be confirmed with similar studies with a larger population.

The limitations of this protocol correspond to the nature of the test used, since it does not establish a definitive diagnosis, but rather a detection of $\mathrm{MCl}$. Since this is an $\mathrm{MCl}$ detection study, it is restricted to predicting the participants' prognosis with certainty, and their follow-up is therefore required to outline their development in relation to their cognitive function.

\section{Conclusions}

In this study, the effect caused by hypertension on the cognitive function of patients aged 45-65 years was observed. Most analyzed participants who met the inclusion and exclusion criteria were detected to have an average score lower than the normal range. By means of the MoCA test, the magnitude of cognitive impairment in these patients could be quantified and, together with Spearman and Pearson's correlations, the trend in the relationship of hypertension with cognitive function could be observed.

\section{Acknowledgments}

The authors express their gratitude to Sociedad Ecuatoriana de Cardiología Núcleo Guayas, to the authorities of the Faculty of Medical Sciences of Universidad de Guayaquil, and to Fuad Huamán Garaicoa, Daniel Tettamanti Miranda, Yan C. Duarte Cáceres and Alejandro A. Flor Márquez for their collaboration to this manuscript.

\section{Funding}

This research has not received any specific grant from agencies of the public, commercial, or non-profit sectors.

\section{Conflict of interests}

None.

\section{Ethical disclosures}

Protection of human and animal subjects. The authors declare that the procedures followed were in compliance with the regulations of the relevant ethics committee for responsible experimentation with human subjects and in accordance with the World Medical Association and the Declaration of Helsinki.

Confidentiality of data. The authors declare that they have followed the protocols of their work center on the publication of patient data.

Right to privacy and informed consent. The authors have obtained informed consent from the patients and/or subjects referred to in the article. This document is in the possession of the corresponding author.

\section{References}

1. American Psychiatric Association, American Psychiatric Association, editors. Diagnostic and statistical manual of mental disorders: DSM-5. $5^{\text {th }}$ ed. Washington, D.C: American Psychiatric Association, 2013.

2. Prince M, Wimo A, Guerchet M, Ali G-C, Wu Y-T, Prina M. World Alzheimer Report 2015. The Global Impact of Dementia. An analysis of prevalence, incidence, cost and trends. 2015.

3. Freire WB, Rojas E, Pazmiño L, Fornasini M, Tito S, Buendía P, et al. Encuesta Nacional De Salud, Bienestar y Envejecimiento: SABE I Ecuador 2009-2010. MIES

4. Petersen RC, Caracciolo B, Brayne C, Gauthier S, Jelic V, Fratiglioni L. Mild cognitive impairment: a concept in evolution. Journal of Internal Medicine. 2014;275(3):214-28.

5. Goldstein F, Levey A, Steenland N. High blood pressure and cognitive decline in mild cognitive impairment. Journal of the American Geriatrics Society. 2013;61(1):67-73. 
6. Rocca WA, Petersen RC, Knopman DS, Hebert LE, Evans DA, Hall KS et al. Trends in the incidence and prevalence of Alzheimer's disease, dementia, and cognitive impairment in the United States. Alzheimer's \& Dementia. 2011;7(1):80-93.

7. Whitney KA, Mossbarger B, Herman SM, Ibarra SL. Is the Montreal Cognitive Assessment superior to the Mini-Mental State Examination in detecting subtle cognitive impairment among middle-aged outpatient U.S. Military Veterans? Archives of Clinical Neuropsychology. 2012;27(7):742-8

8. Knopman D, Petersen R. Mild cognitive impairment and mild dementia a clinical perspective. Mayo Clinic Proceedings. 2014;89(10):1452-1459.

9. Petersen RC, Roberts RO, Knopman DS, Boeve BF, Geda YE, Ivnik RJ, et al. Mild cognitive impairment: ten years later. Arch Neurol. 2009;66(12):1447.

10. Brambati S, Belleville S, Kergoat M, Chayer C, Gauthier S, Joubert S. Single- and multiple-domain amnestic mild cognitive impairment: two sides of the same coin? 2018.

11. Csukly G, Sirály E, Fodor Z, Horváth A, Salacz P, Hidasi Z, et al. The differentiation of amnestic type $\mathrm{MCl}$ from the non-amnestic types by structural MRI. Frontiers in Aging Neuroscience. 2016;8.

12. Kwong LK, Neumann M, Sampathu DM, Lee VM, Trojanowski JQ. DP-43 proteinopathy: the neuropathology underlying major forms of sporadic and familial frontotemporal lobar degeneration and motor neuron disease. Acta Neuropathol. 2007;114(1):63. Epub 2007 May 10

13. Geda YE, Roberts, Knopman DS, Petersen RC, Christianson TJ, Pankratz VS, et al. Prevalence of neuropsychiatric symptoms in mild cognitive impairment and normal cognitive aging: population-based study. Arch Gen Psychiatry. 2008;65(10):1193.

14. Gabryelewicz T, Styczynska M, Pfeffer A, Wasiak B, Barczak A, Luczywek $\mathrm{E}$, et al. Prevalence of major and minor depression in elderly persons with mild cognitive impairment--MADRS factor analysis. Int $J$ Geriatr Psychiatry. 2004;19(12):1168-72.
15. Langa $K$, Levine $D$. The diagnosis and management of mild cognitive impairment. JAMA. 2014;312(23):2551.

16. Clarfield AM. The decreasing prevalence of reversible dementias: an updated meta-analysis. Arch Intern Med. 2003;163(18):2219-2229.

17. Cai X, Campbell N, Khan B, Callahan C, Boustani M. Long-term anticholinergic use and the aging brain. Alzheimer's \& dementia: The Journal of the Alzheimer's Association. 2013;9(4):377-385.

18. Karakaya T, Fußer F, Schroder J, Pantel J. Pharmacological treatment of mild cognitive impairment as a prodromal syndrome of Alzheimer's disease. Current Neuropharmacology. 2013;11(1):102-108.

19. In't Veld BA, Ruitenberg A, Hofman A, Stricker BH, Breteler MM. Antihypertensive drugs and incidence of dementia: the Rotterdam Study. Neurobiol Aging. 2001;22(3):407-12.

20. Knopman D, Boland LL, Mosley T, Howard G, Liao D, Szklo M, et al. Cardiovascular risk factors and cognitive decline in middle-aged adults. Neurology. 2001;56(1):42.

21. Tzourio $C$, Dufouil $C$, Ducimetière $P$, Alpérovitch $A$. Cognitive decline in individuals with high blood pressure: a longitudinal study in the elderly. EVA Study Group. Epidemiology of Vascular Aging. Neurology. 1999;53(9):1948-52.

22. Muela HCS, Costa-Hong VA, Yassuda MS, Moraes NC, Memória CM, Machado MF, et al. Hypertension severity is associated with impaired cognitive performance. J Am Heart Assoc. 2017;6(1).

23. Vicario A, Martínez CD, Baretto D, Díaz Casale A, Nicolosi L. Hypertension and cognitive decline: impact on executive function. J Clin Hypertens (Greenwich). 2005;7(10):598-604.

24. Yaffe K, Vittinghoff E, Pletcher MJ, Hoang TD, Launer LJ, Whitmer R, et al. Early adult to midlife cardiovascular risk factors and cognitive function. Circulation. 2014:129(15):1560-7.

25. Livingston G, Sommerlad A, Orgeta V, Costafreda SG, Huntley J, Ames D, et al. Dementia prevention, intervention, and care. Lancet. 2017;390(10113):2673. Epub 2017 Jul 20. 